\title{
ZUSES
}

\section{u.s. Department of the Imerici}

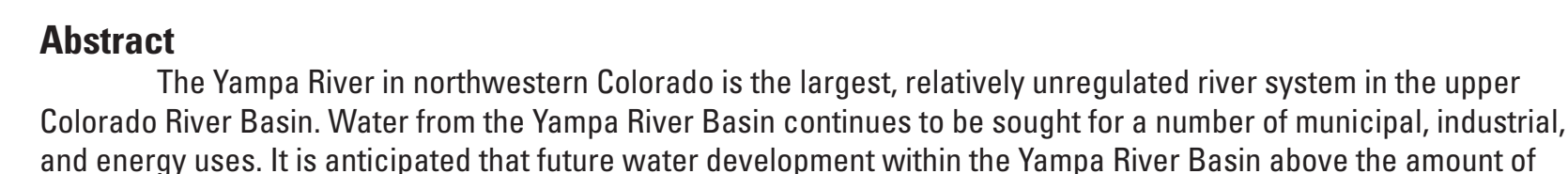

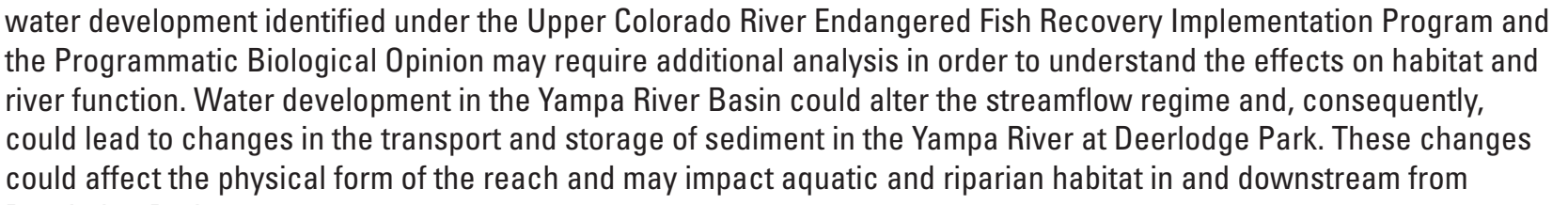

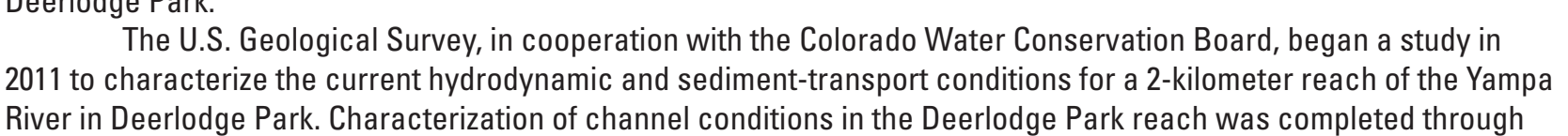

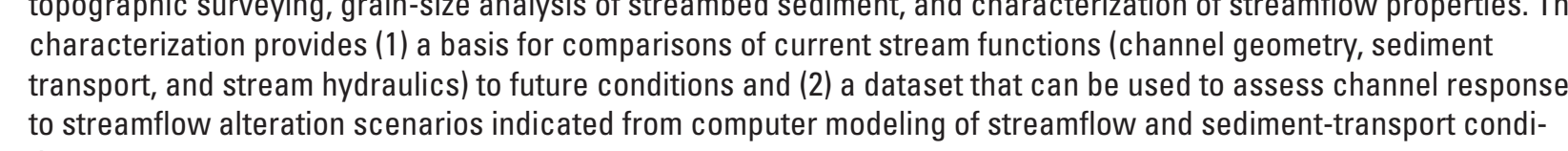

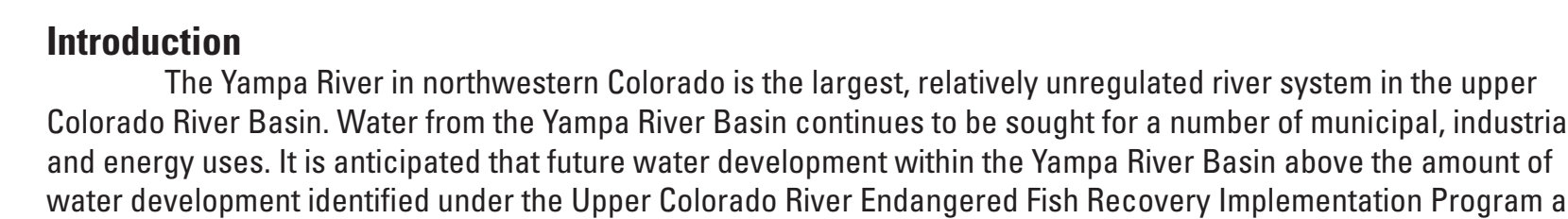

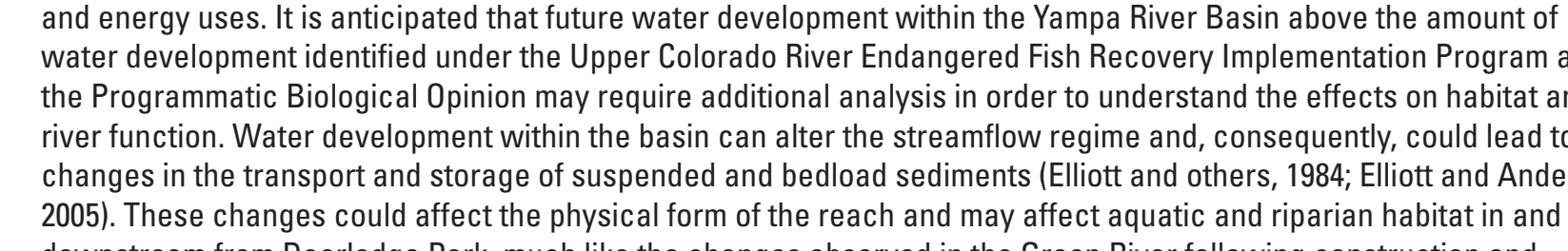

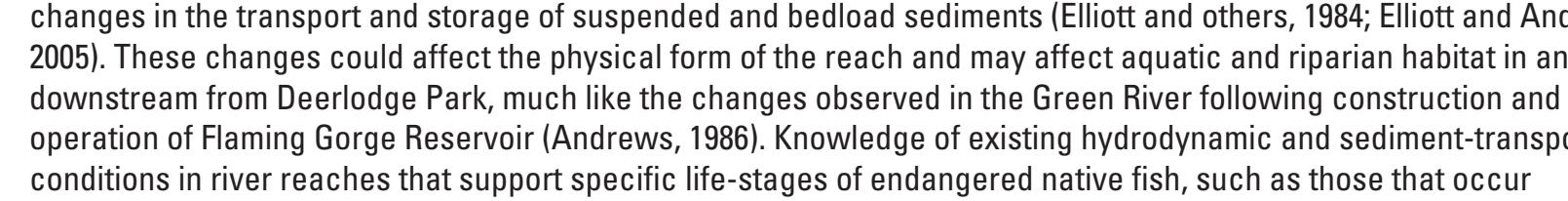

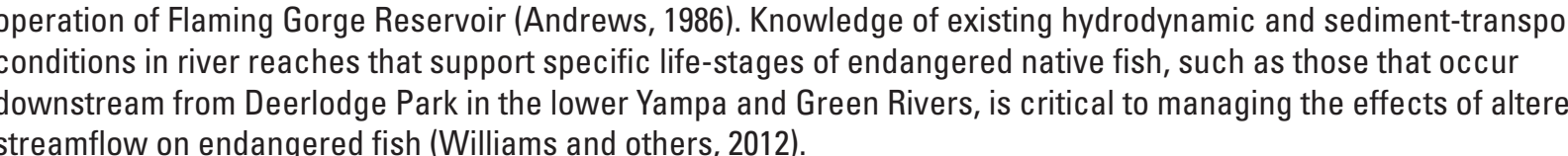

Puppsesent scope

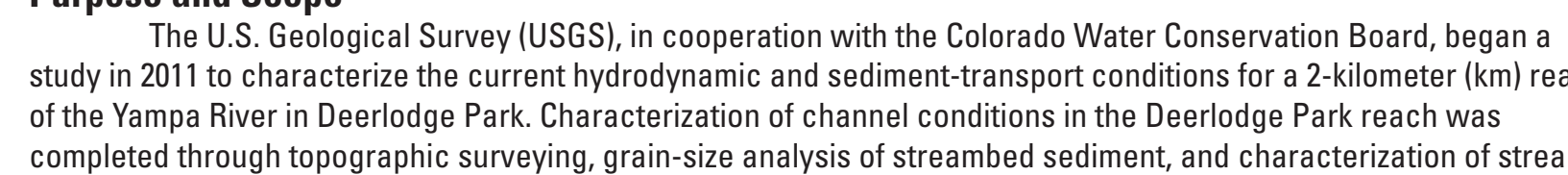

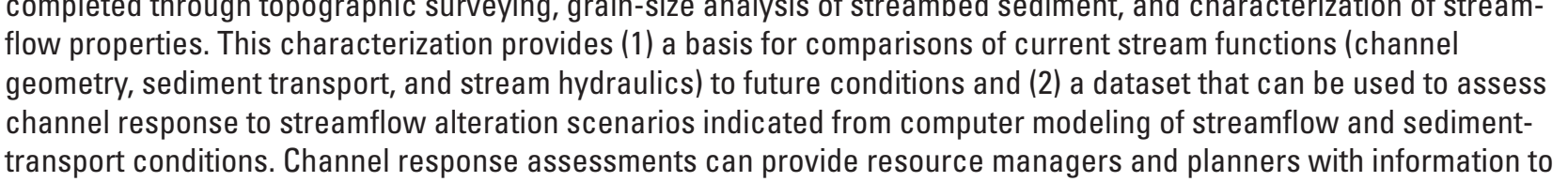

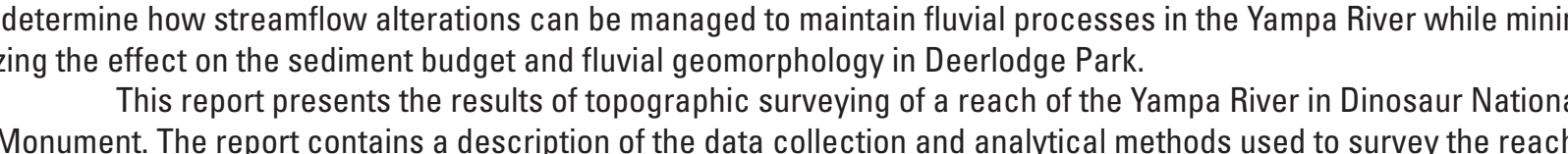

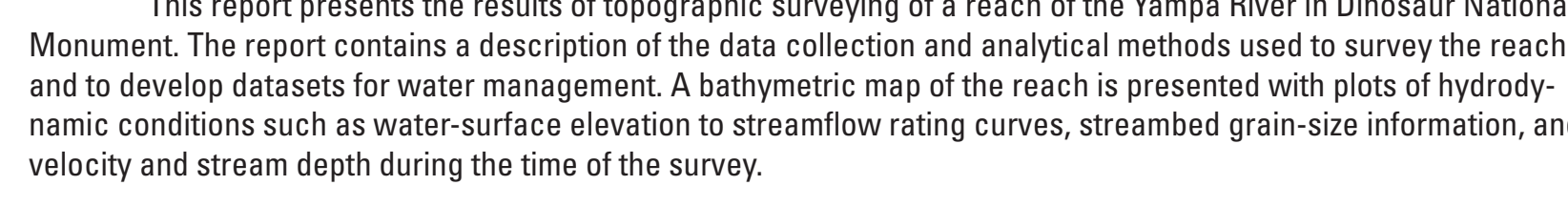
Descripition of Studu Area

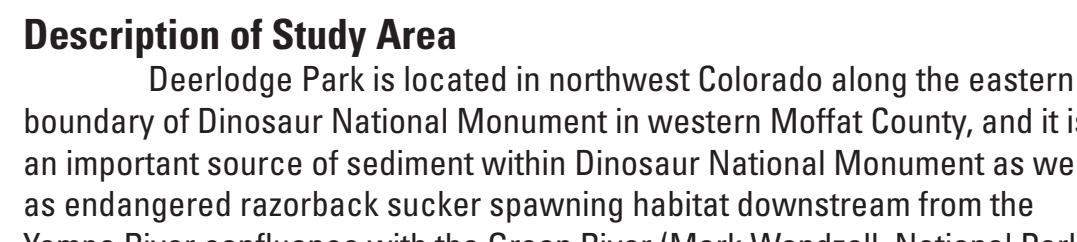

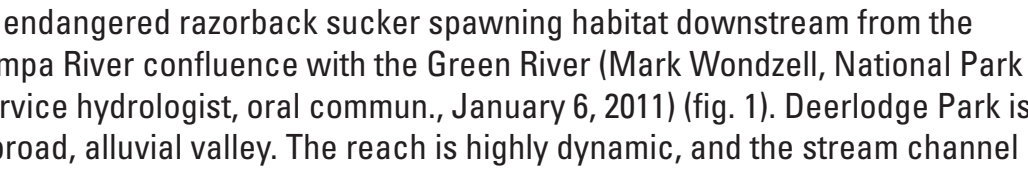

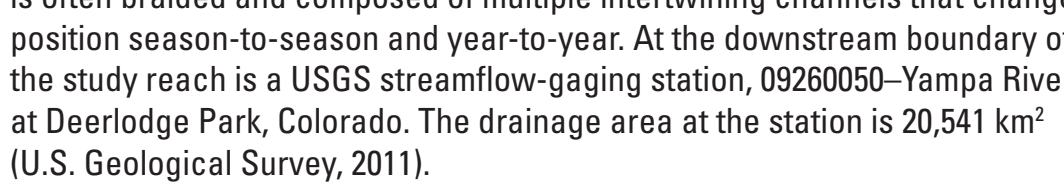

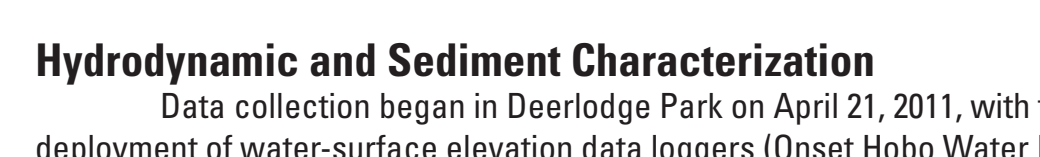

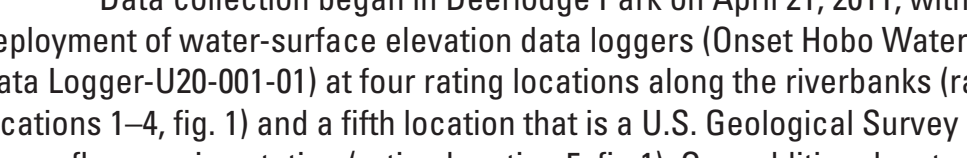

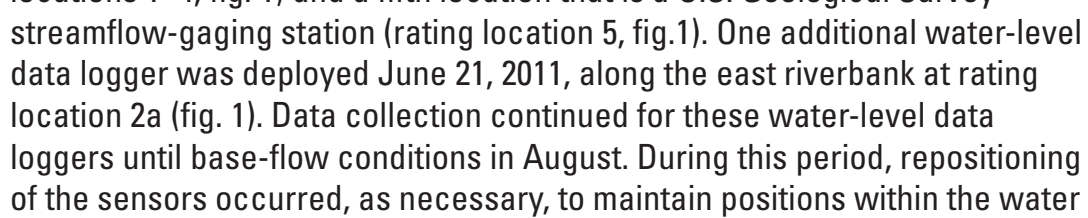

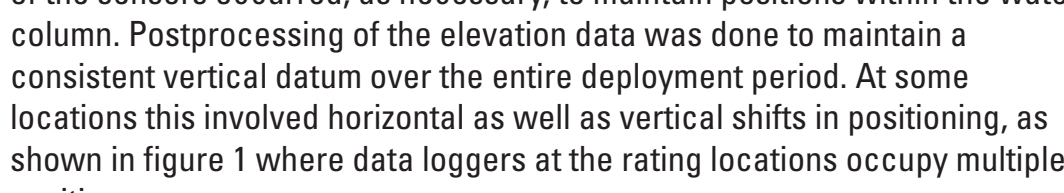

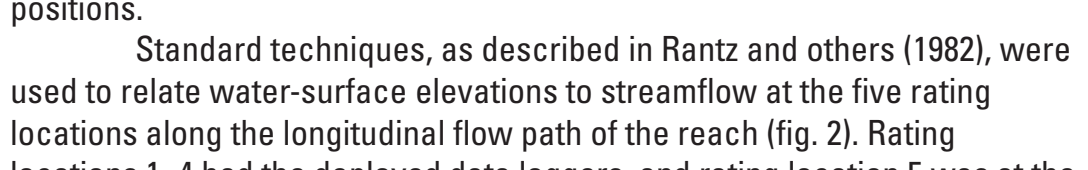

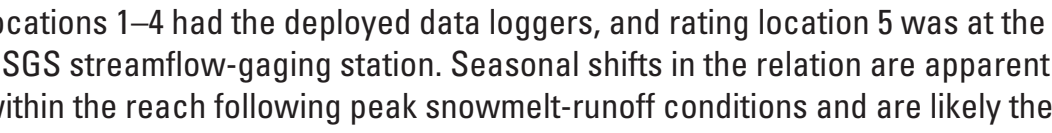

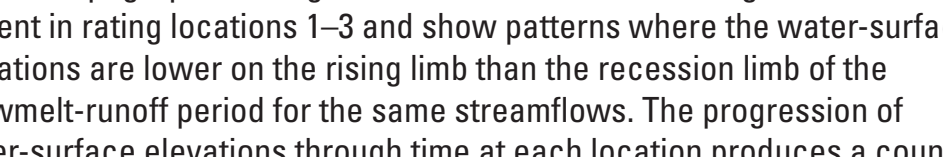

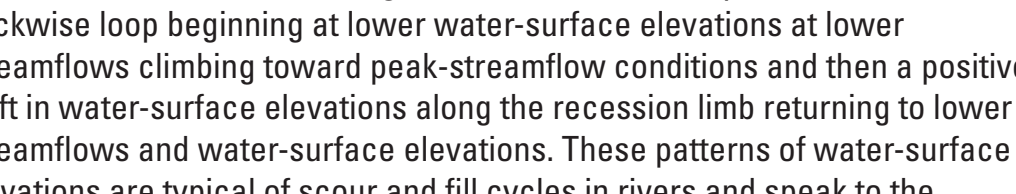

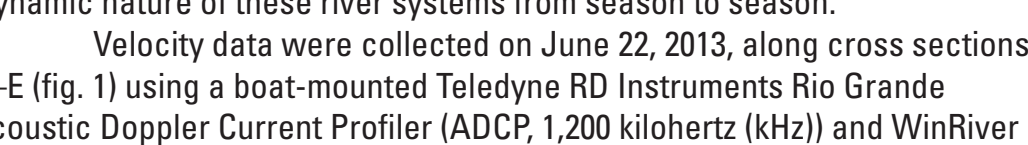

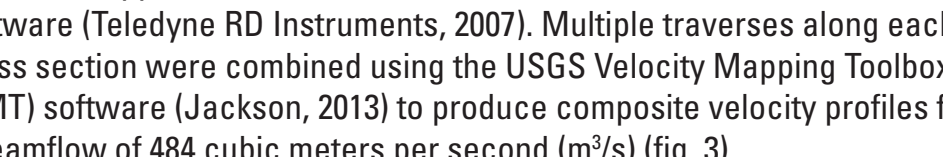

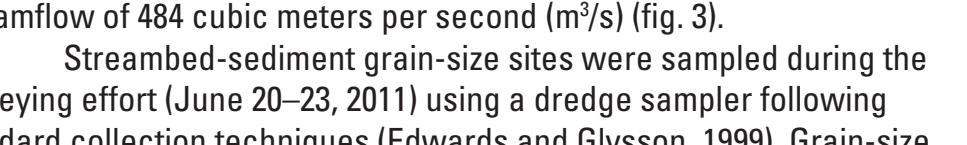

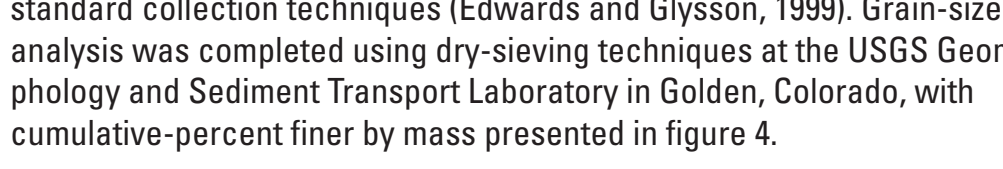

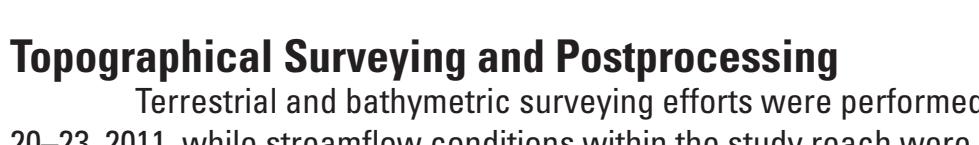

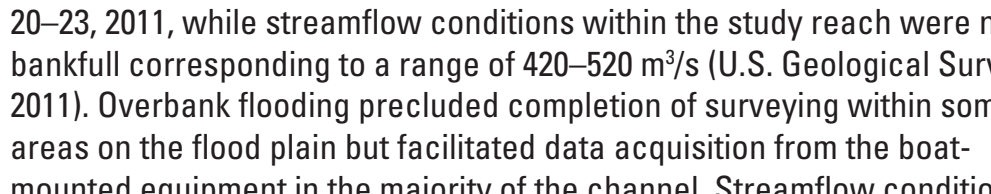

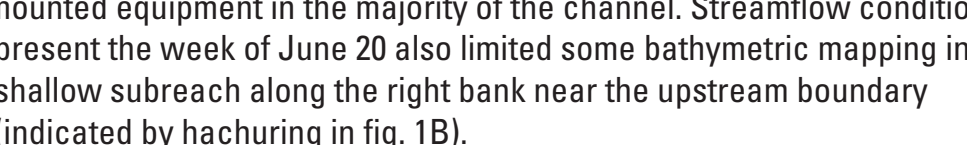

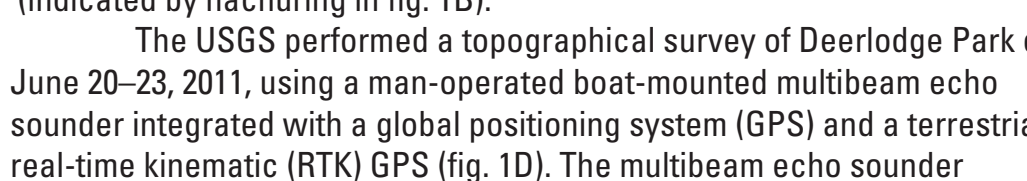

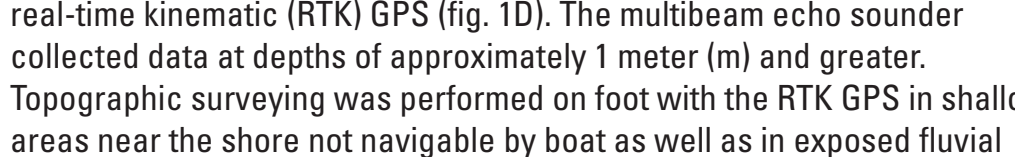

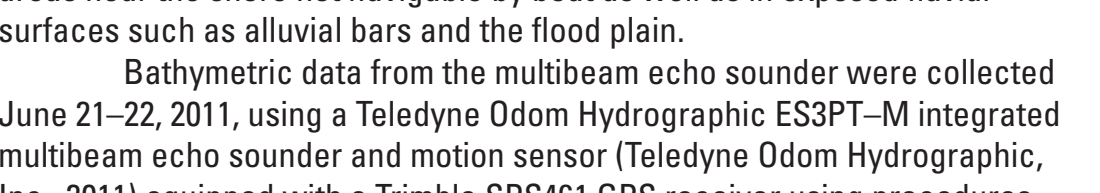

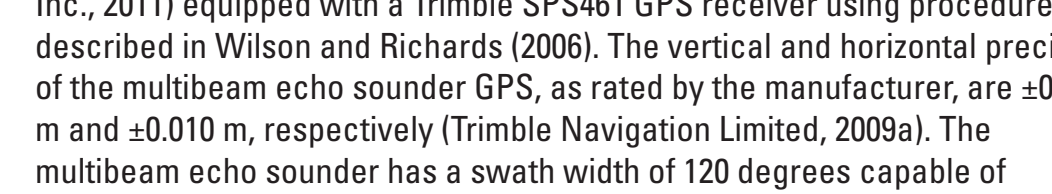
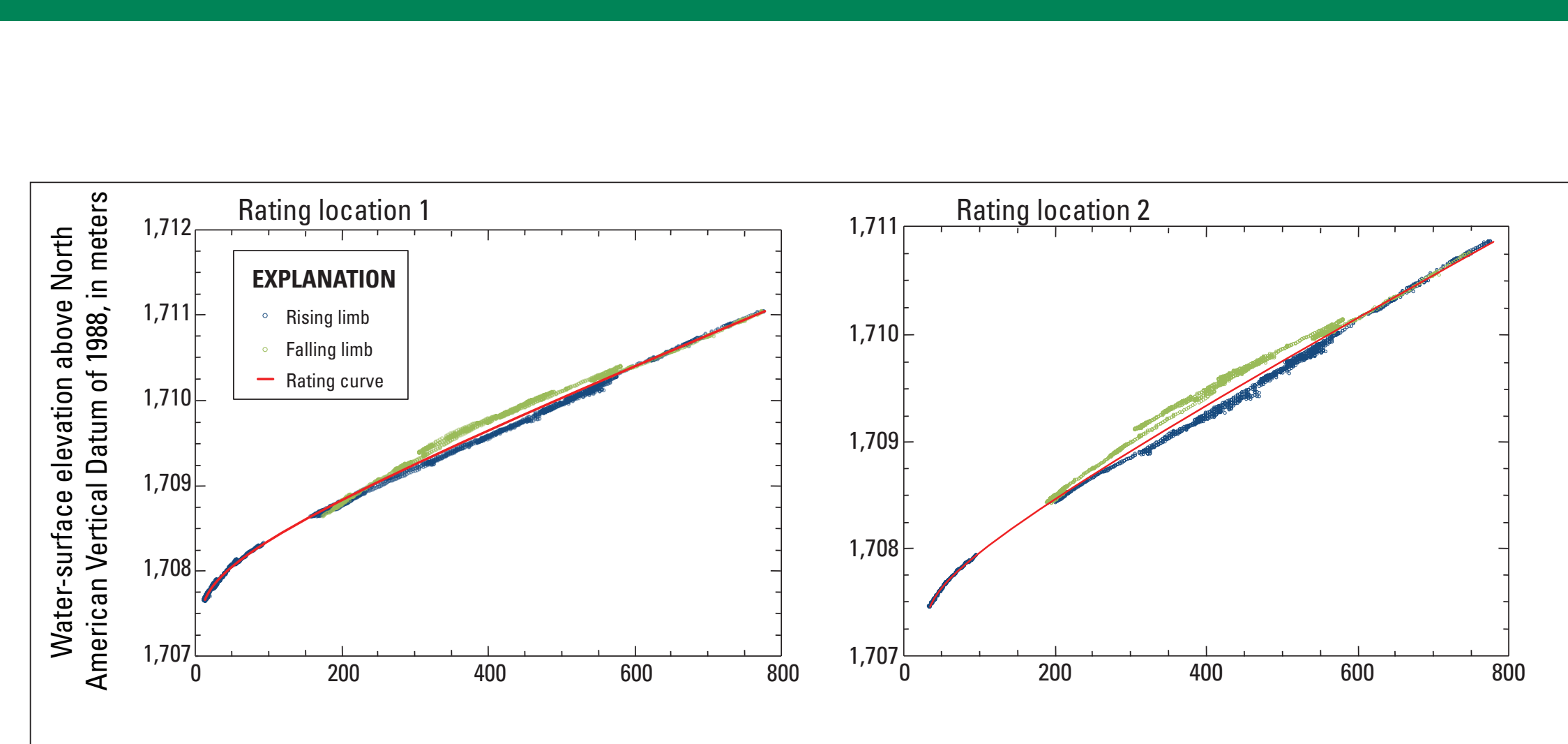

\section{Prepared in cooperation with hine
Colorara W Water Conservation Board}
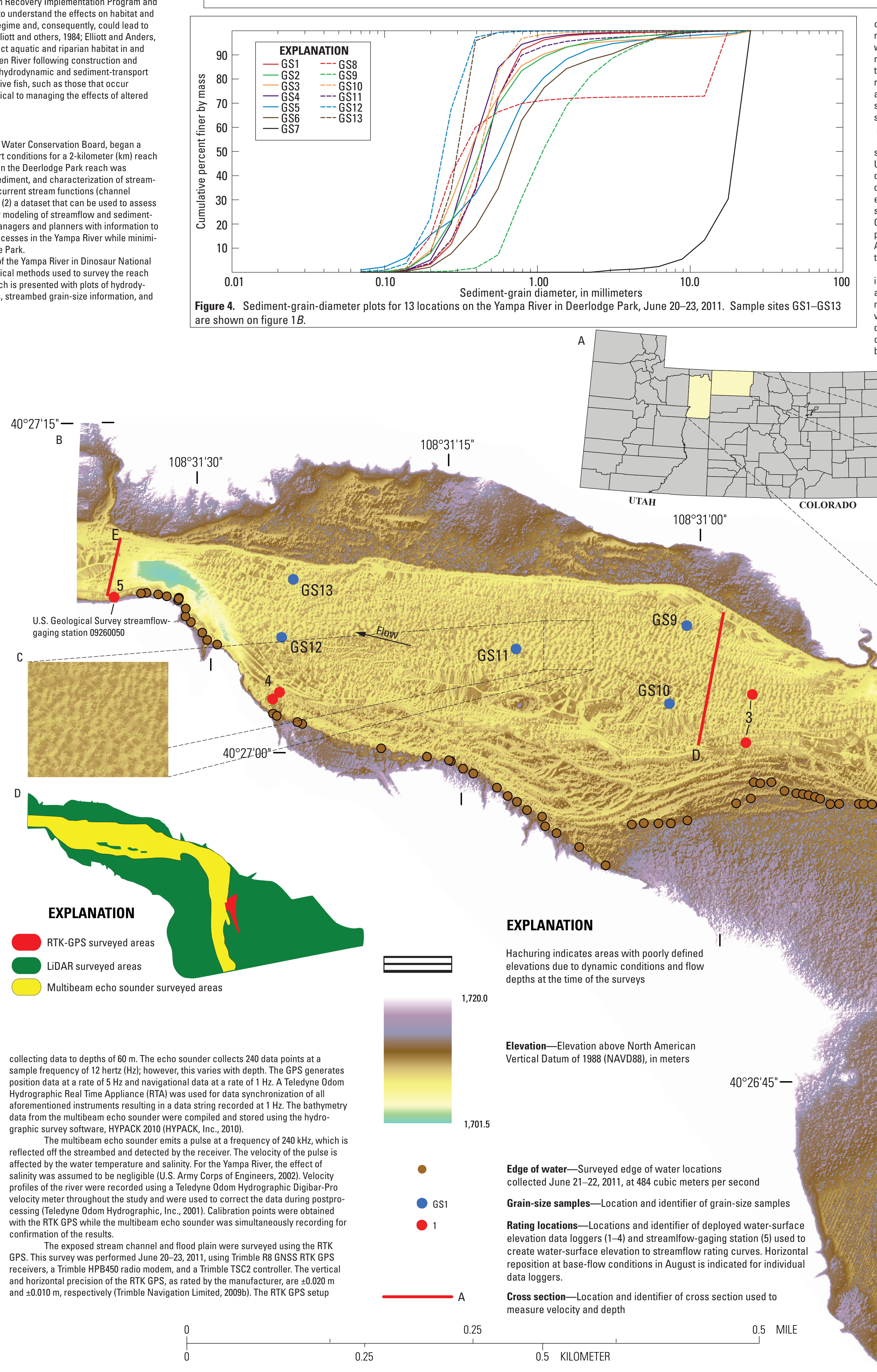
0.5 KLLOEEE 0.5 MLE

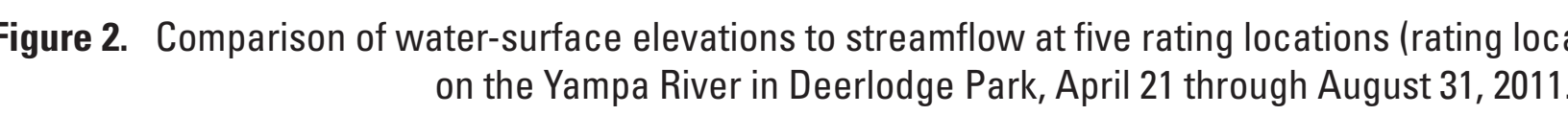
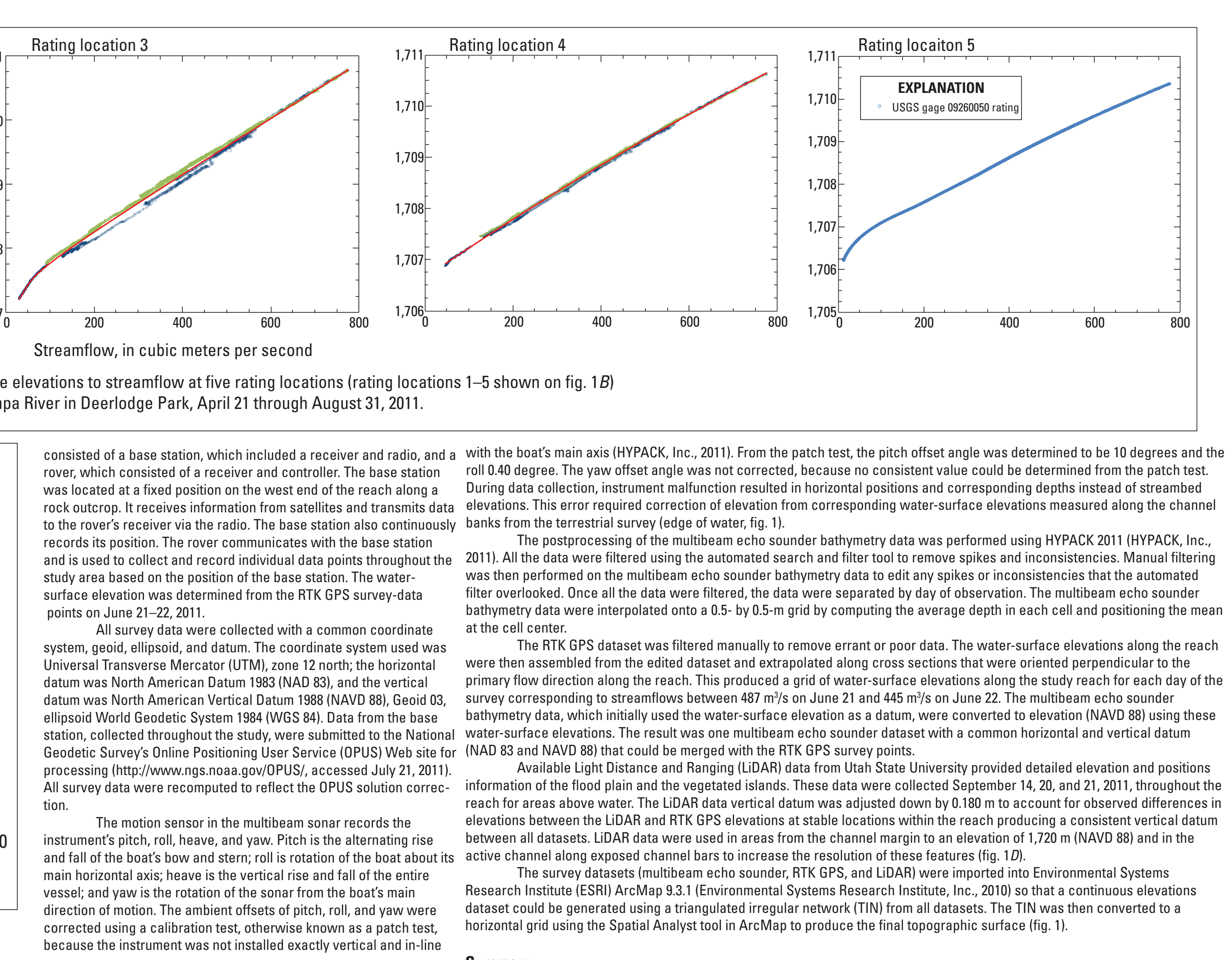

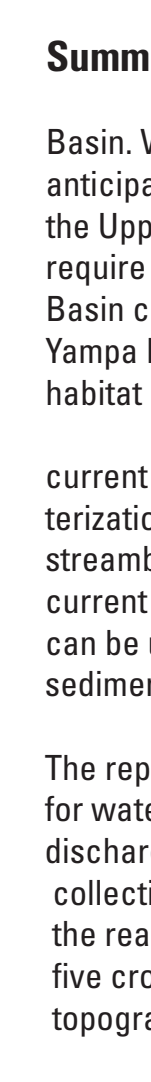

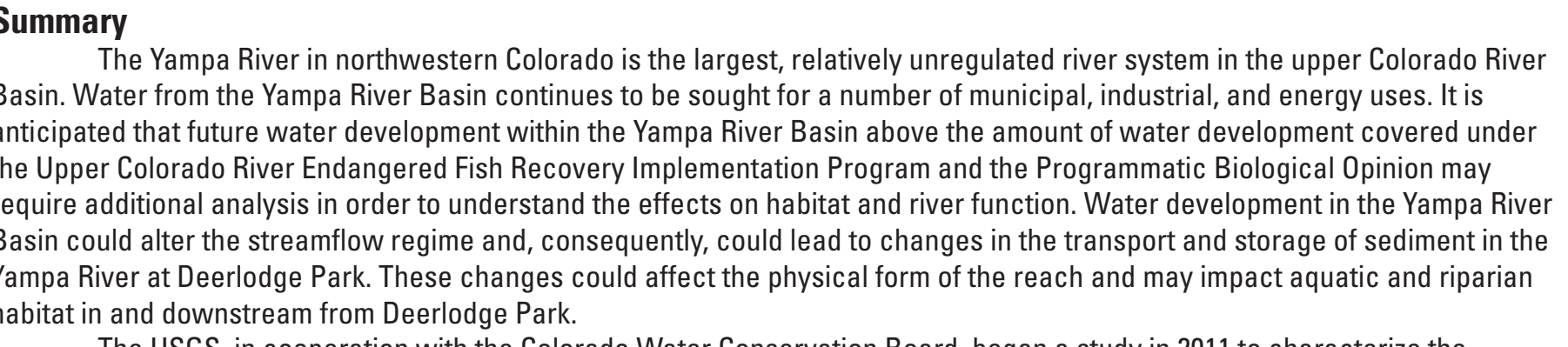

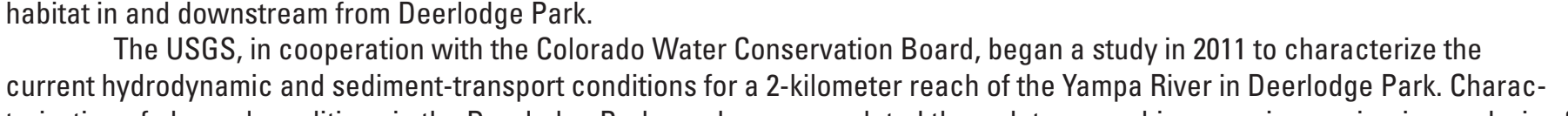

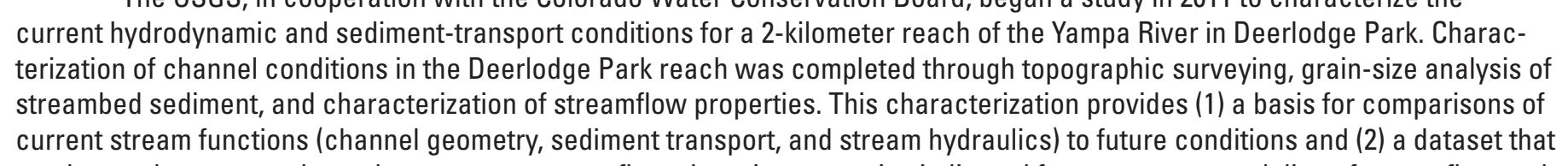

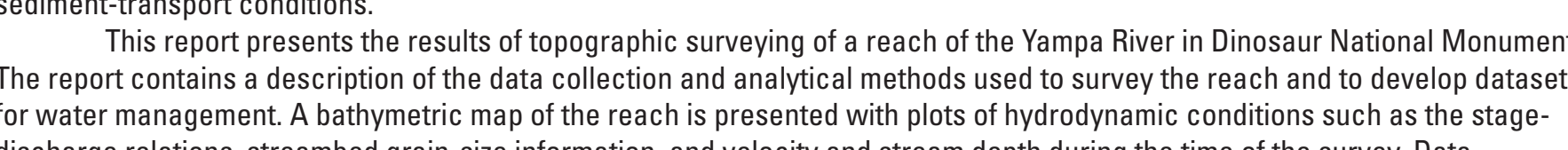

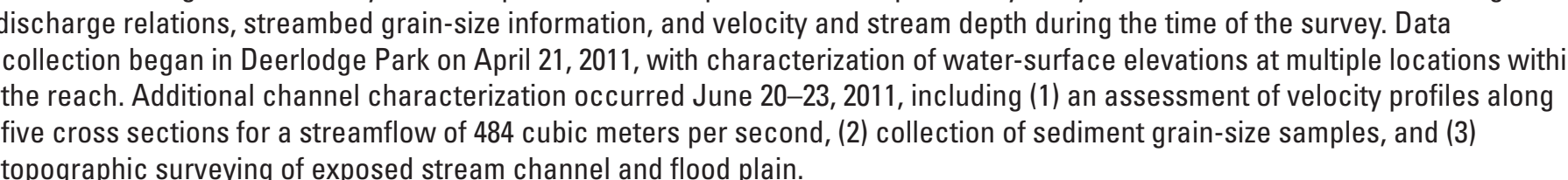
Reterences Citín

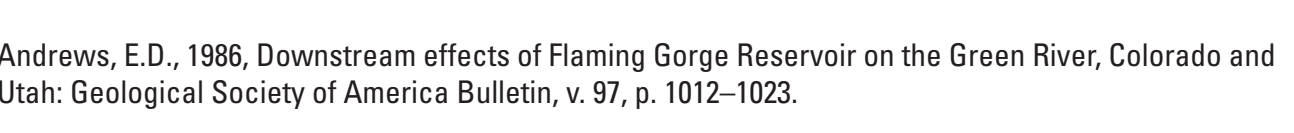

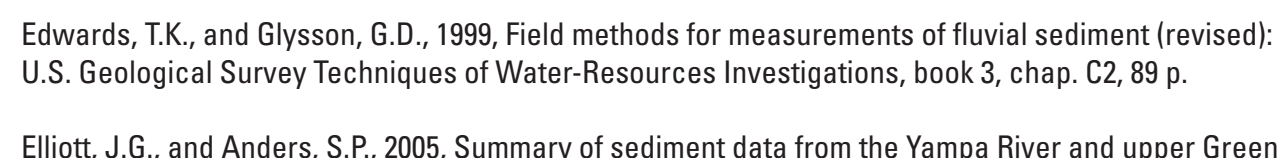

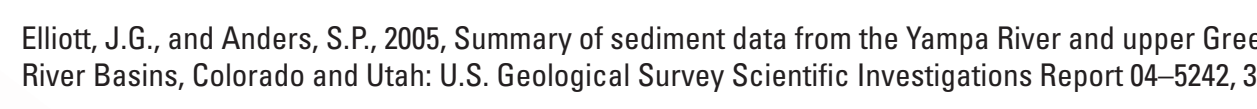

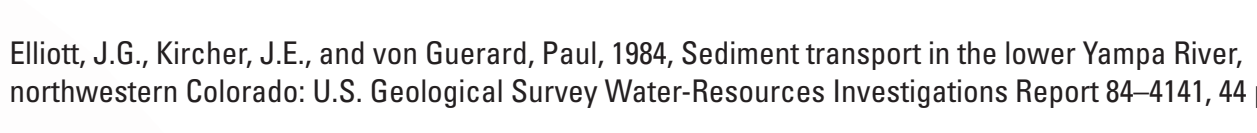

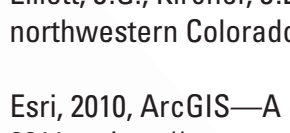

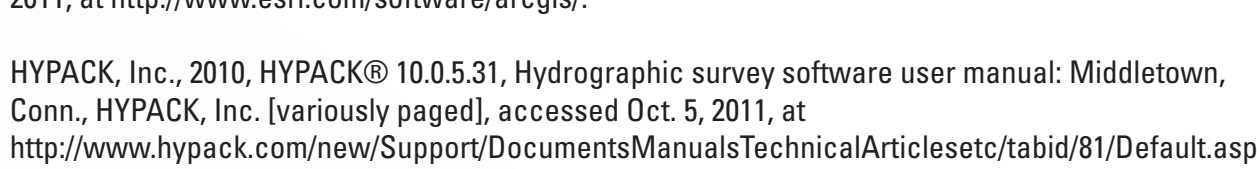
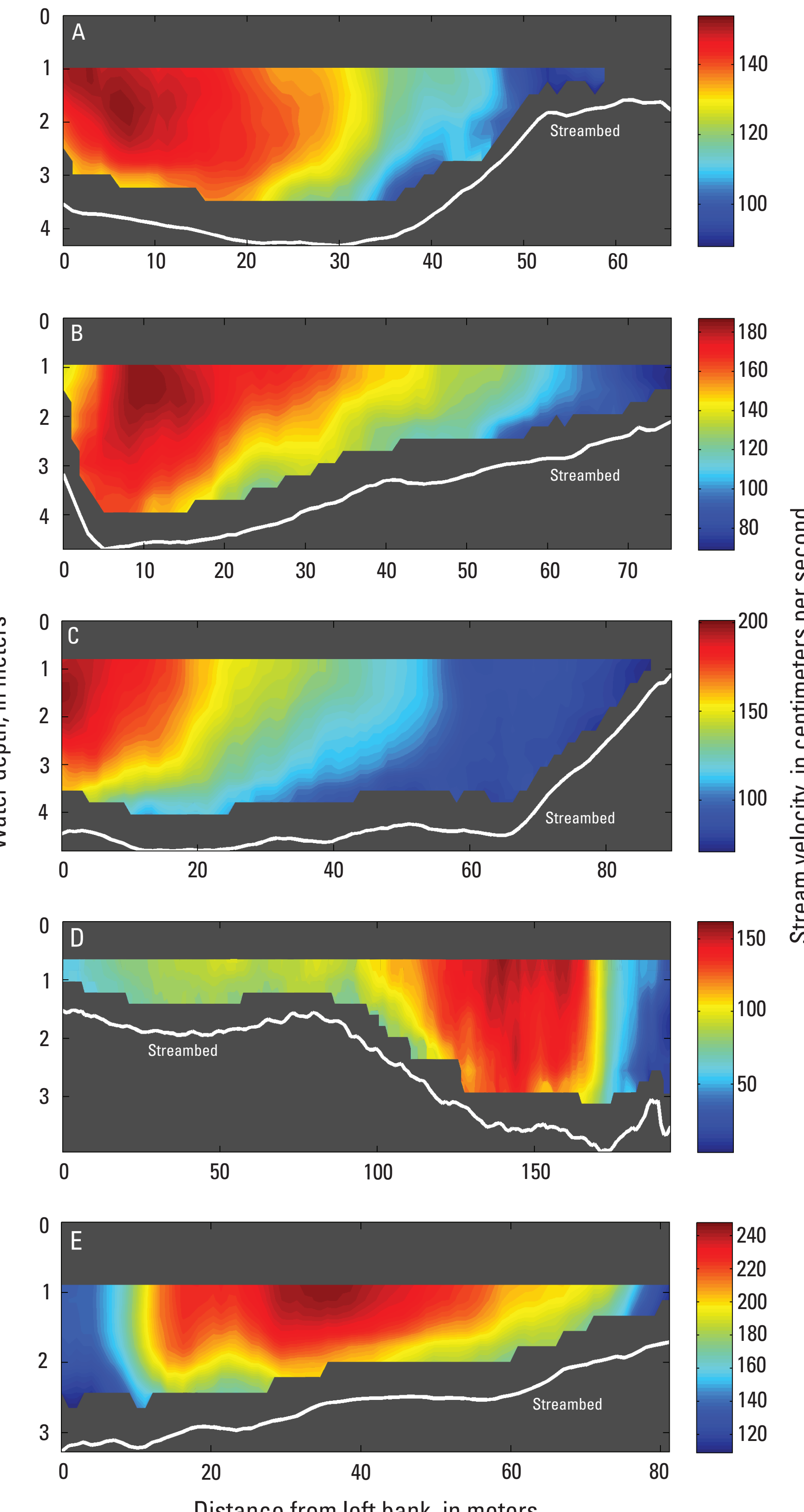

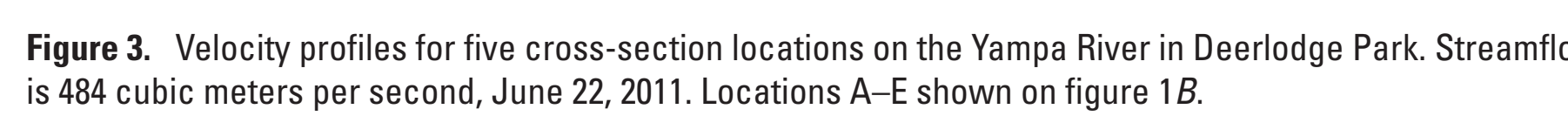

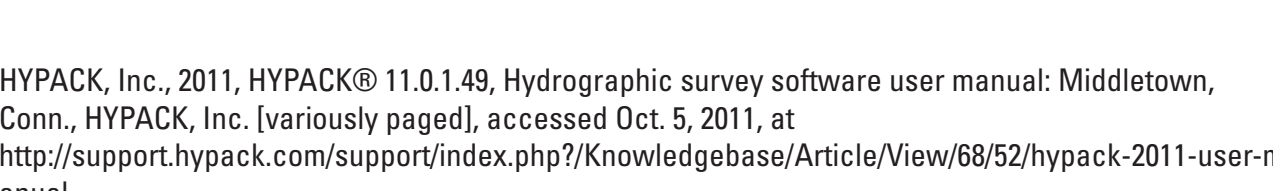

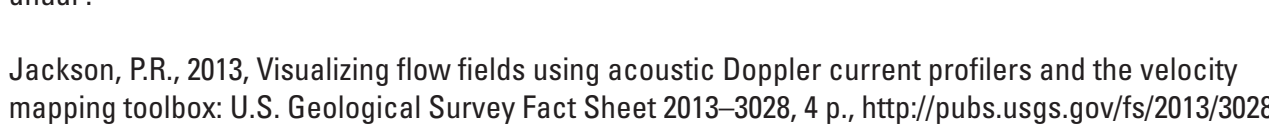

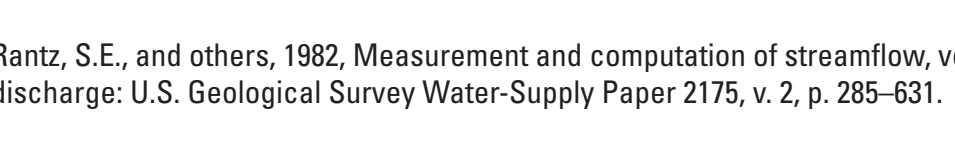

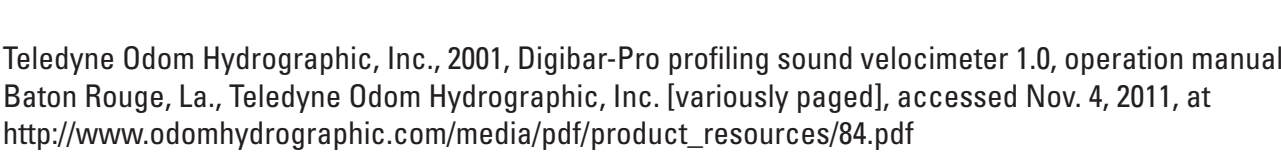

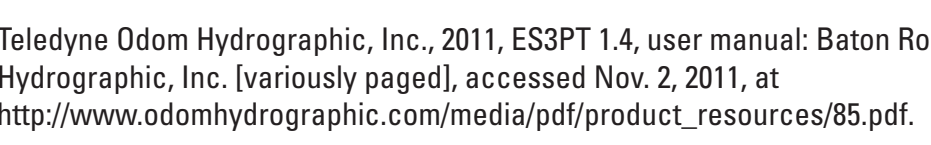

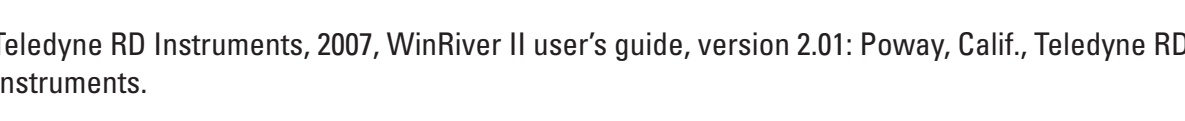

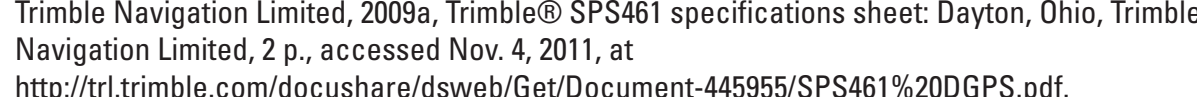

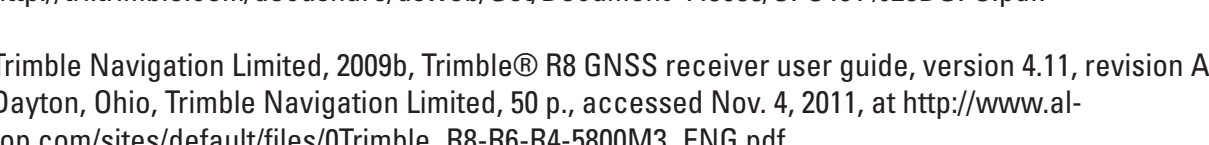

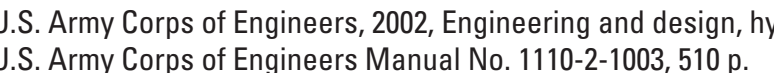

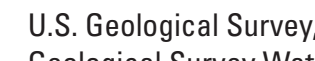

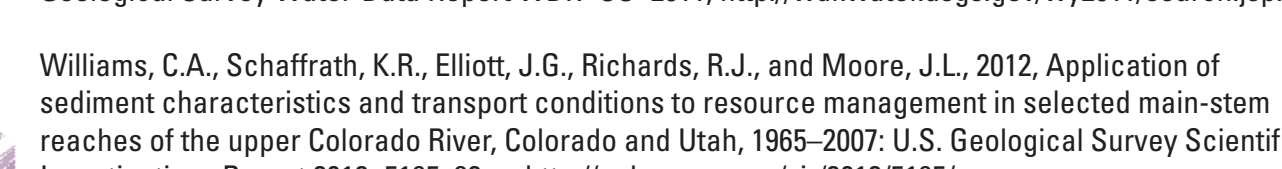

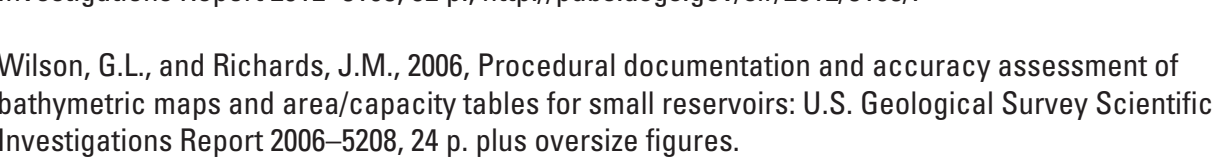

Characterization of Hydrodynamic and Sediment Conditions in the Lower Yampa River at Deerlodge Park East Entrance to Dinosaur National Monument, Northwest Colorado, 2011

$$
\begin{aligned}
& \text { By } \\
& \text { Cory A. Williams } \\
& 2013
\end{aligned}
$$

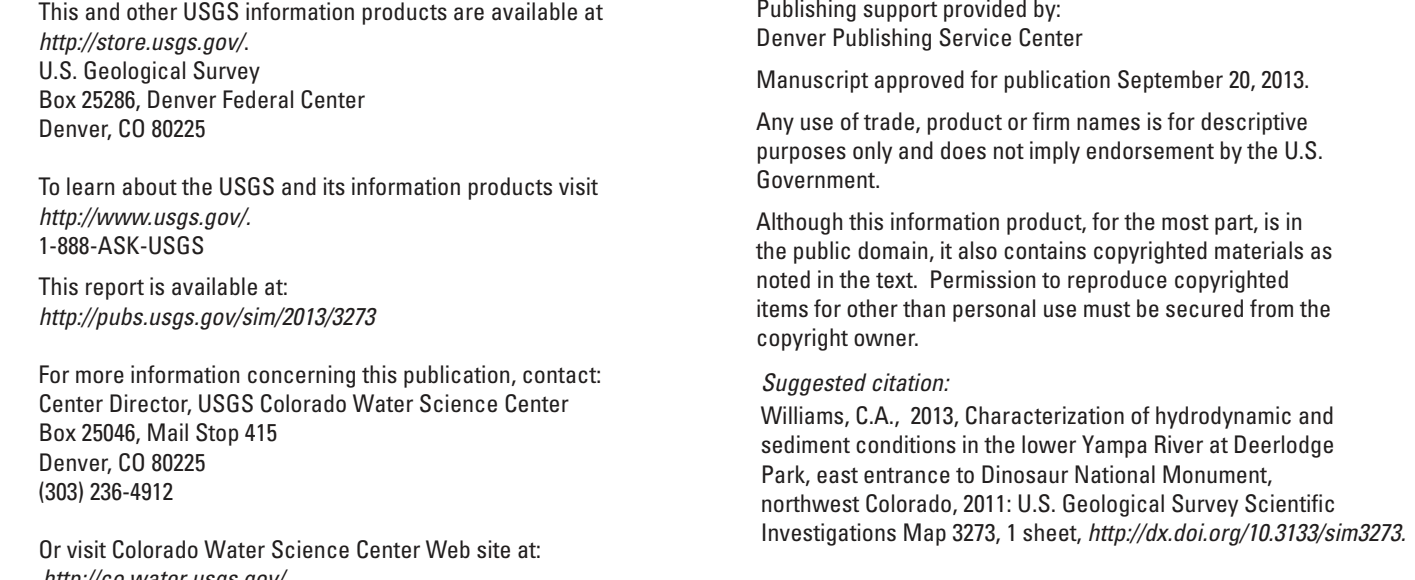

